\title{
Pelletizing Analysis on MgO-Fluxed Pellets by DEM
}

\author{
Fang Long ${ }^{1,2}$, Fengman Shen ${ }^{1, *}$, Xin Jiang ${ }^{1, *}$, Fu Yang ${ }^{3}$, Yulu Zhou ${ }^{1}$ and Haiwei An ${ }^{1}$ \\ 1 School of Metallurgy, Northeastern University, Shenyang 110819, China; 1810523@stu.neu.edu.cn (F.L.); \\ 1901571@stu.neu.edu.cn (Y.Z.); 2010600@stu.neu.edu.cn (H.A.) \\ 2 Anyang Iron \& Steel Group Co., Ltd., Anyang 455000, China \\ 3 College of Resources and Environmental Engineering, Wuhan University of Science and Technology, \\ Wuhan 430065, China; yangfu@wust.edu.cn \\ * Correspondence: shenfm@mail.neu.edu.cn (F.S.); jiangx@smm.neu.edu.cn (X.J.)
}

check for

updates

Citation: Long, F.; Shen, F.; Jiang, X.; Yang, F.; Zhou, Y.; An, H. Pelletizing Analysis on MgO-Fluxed Pellets by DEM. Crystals 2021, 11, 821. https:// doi.org/10.3390/cryst11070821

Academic Editors: Yufeng Guo, Shuai Wang, Mao Chen, Kexin Jiao, Lingzhi Yang, Feng Chen and Fuqiang Zheng

Received: 23 June 2021

Accepted: 12 July 2021

Published: 15 July 2021

Publisher's Note: MDPI stays neutral with regard to jurisdictional claims in published maps and institutional affiliations.

Copyright: (C) 2021 by the authors Licensee MDPI, Basel, Switzerland. This article is an open access article distributed under the terms and conditions of the Creative Commons Attribution (CC BY) license (https:/ / creativecommons.org/licenses/by/ $4.0 /)$.

\begin{abstract}
The Discrete Element Method (DEM) was used to analyze the pelletization process of $\mathrm{MgO}$-fluxed pellets. The effects of the charge ratio and rotational speed of the disc pelletizer on the behavior of $\mathrm{MgO}$-fluxed pellets were investigated by using a simulation. The simulation results show that under the condition of a certain tilt angle of the disc pelletizer (the tilt angle is $49^{\circ}$ ), the suitable parameters of the disc pelletizer are that the charge ratio is $20 \%$ and the rotational speedis $0.7 \mathrm{~N} / \mathrm{NC}$. This simulation model proposed will be useful to research pellets behavior and for the design of disc pelletizers.
\end{abstract}

Keywords: MgO-fluxed pellets; disc pelletizer; discrete element method; charge ratio; rotational speed

\section{Introduction}

Traditional acid pellets, as a kind of burden of blast furnace, have many advantages, such as high ambient temperature compressive strength, uniform size, and high iron grade. The higher the pellet ratio in burden of blast furnace is, the higher the production is. Moreover, the pellet production process also has the characteristics of low energy consumption and low pollution. Therefore, the consumption of acid pellets has been gradually increasing. Nevertheless, compared with sinters, the acid pellets have some deficiencies, such as lower softening and melting temperature, wider softening drop temperature range, poorer permeability of cohesive zone, and higher reduction swelling [1]. The proportion of pellets in BFs in China is approximately 10 25\% [2,3]. In order to increase the proportion of pellets in blast furnace burden and improve the metallurgical properties of pellets at high temperature, fluxed pellets have recently been widely developed, especially $\mathrm{MgO}$-fluxed pellets, which have better high-temperature metallurgical properties, such as reduction swelling properties, softening-melting properties, and a high reduction disintegration index. Additionally, it can meet the requirement of $\mathrm{MgO}$ content in $\mathrm{BF}$ slag. MgO-fluxed pellets can make the blast furnaces have a more reasonable cohesive zone, improve permeability and ensure the reasonable distribution of gas. Moreover, the blast furnaces are stable and run smoothly so that the production of them increases and coke ratio decreases [4-11].

The metallurgical properties of $\mathrm{MgO}$-fluxed pellets have been studied in many literatures. However, there are few studies on the influence of production technical parameters, such as rotational speed and charge ratio of the disc pelletizer, on the pelletizing performance of raw materials. In the current study, efforts have been made to understand the effects of varying the rotational speed and charge ratio of the disc pelletizer on the pelletizing performance of $\mathrm{MgO}-$ fluxed pellets raw materials. As we all know, the production process of green pellets can be divided into three stages: the nucleation stage, growing stage, and compact stage. The effect of moisture is mainly reflected in the first two stages. After the formation of green pellets, the improvement of green pellets' strength mainly depends on the mechanical rolling force. This study mainly focused on the effects of the charge ratio and rotational speed of the disc pelletizer on the final green pellets' 
performance, so the effect of moisture on the pelletizing process was ignored. There is no considerable number of papers that report on the effect of production technical parameters for MgO-fluxed pellets. The results can provide a theoretical basis and technical guidance for industrial production of $\mathrm{MgO}$-fluxed pellets.

\section{Principle of the Discrete Element Method (DEM) and Simulation Conditions}

The interaction forces in collision between two particles, between particles and boundary, are represented by the normal vibration model, tangential vibration model, and tangential sliding model, as shown in Figure 1 [12].

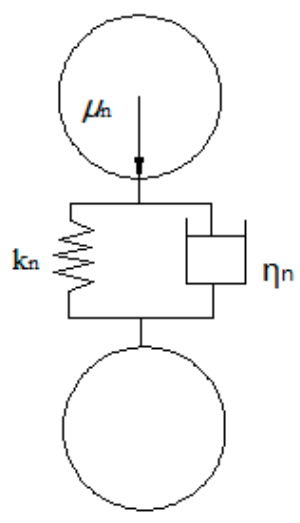

(a)

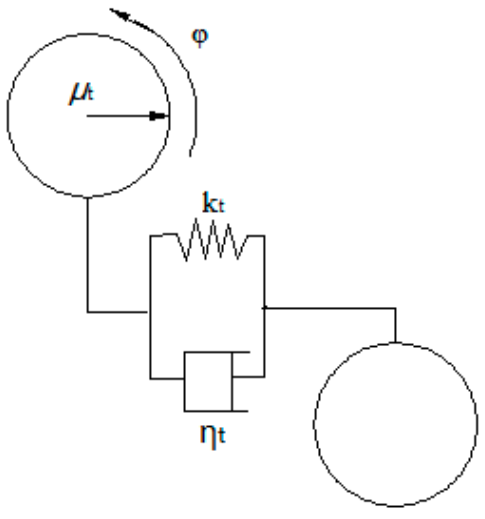

(b)

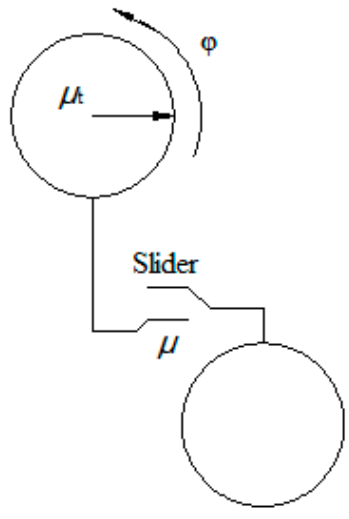

(c)

Figure 1. Principle of the simulation model. (a) normal vibration; (b) tangential vibration; (c) tangential sliding.

The assumptions in this simulation model are follows:

(1) Pellet diameter is uniform.

(2) Pellet diameter and other parameters are fixed in the simulation.

(3) Effect of moisture is ignored.

Simulation conditions are shown in Tables 1 and 2.

Table 1. Material physical parameters.

\begin{tabular}{|c|c|c|c|c|}
\hline Material & Density $\left(\mathrm{kg} / \mathrm{m}^{3}\right)$ & $\begin{array}{c}\text { Shear Modulus } \\
\text { (Pa) }\end{array}$ & Poisson's Ratio & $\begin{array}{l}\text { Bulk Density } \\
\left(\mathrm{kg} / \mathrm{m}^{3}\right)\end{array}$ \\
\hline Disc pelletizer & 7800 & $7 \times 10^{10}$ & 0.30 & - \\
\hline Pellets & 2500 & $1 \times 10^{7}$ & 0.19 & 1800 \\
\hline
\end{tabular}

Table 2. Contact parameters.

\begin{tabular}{cccc}
\hline Contact Material & $\begin{array}{c}\text { Coefficient of } \\
\text { Restitution }\end{array}$ & $\begin{array}{c}\text { Coefficient of Static } \\
\text { Friction }\end{array}$ & $\begin{array}{c}\text { Coefficient of } \\
\text { Rolling Friction }\end{array}$ \\
\hline Pellets-Disc pelletizer & 0.28 & 0.60 & 0.01 \\
Pellet-Pellet & 0.23 & 0.57 & 0.01 \\
\hline
\end{tabular}

Pelletizing is processed in a simulation model with a disc pelletizer of $0.8 \mathrm{~m}$ in diameter and $0.2 \mathrm{~m}$ rim depth, with different rotational speeds and different charge ratios. According to the actual situation of pellet production in the Anyang Iron and Steel Group Co., Ltd., 
the disc inclination angle is set at $49^{\circ}$ horizontally in this study. $N$ is the rotational speed of the disc pelletizer and $\mathrm{Nc}$ is the critical rotational speed given by following equation [13]:

$$
N c=\frac{42.4 f \sqrt{K(\sin \alpha-\sin \Phi)}}{\sqrt{D}}
$$

where, $N c$ and $D$ are the critical rotational speed of the disc pelletizer and the diameter of the disc pelletizer, respectively, $f$ is friction coefficient between raw material and disc pelletizer, $K$ is a regulatory coefficient, $\alpha$ is lean angle of disc pelletizer, and $\Phi$ is a repose angle of raw material.

In this simulation, the ratio of rotational speed to critical rotational speed $(\mathrm{N} / \mathrm{Nc})$ is $0.5,0.6$, $0.7,0.8$, and 0.9 , respectively, and the charge ratio, $C$, is $10 \%, 15 \%, 20 \%$, and $25 \%$ respectively.

\section{Simulation Results and Discussion}

Figure 2 shows motion state of pellets simulated by DEM in the disc pelletizer at $1.2 \mathrm{~s}$ at a charge ratio of $20 \%$ for different rotational speeds.

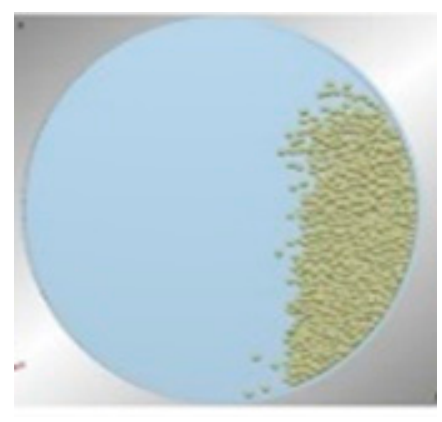

$N / N c=0.5$

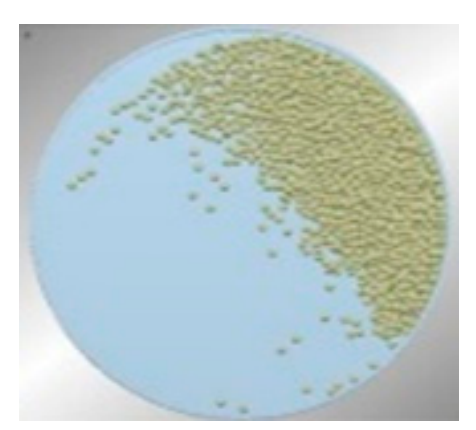

$N / N c=0.8$

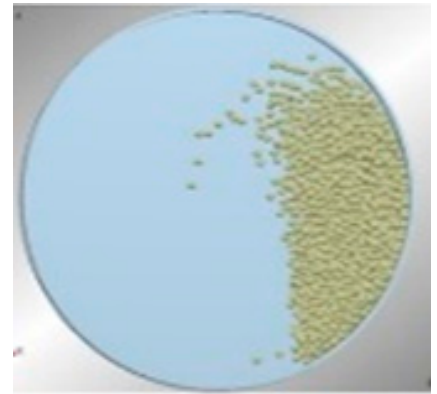

$N / N c=0.6$

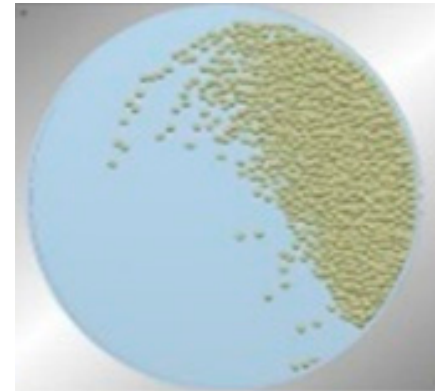

$N / N c=0.7$

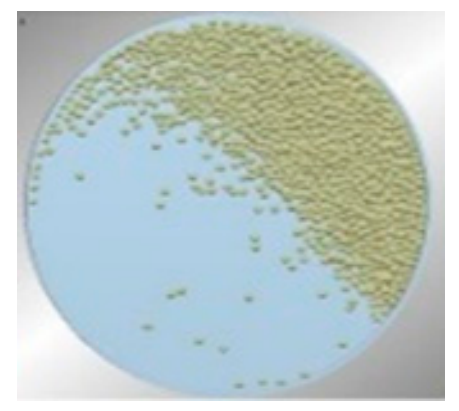

$N / N c=0.9$

Figure 2. Motion state of pellets at $1.2 \mathrm{~s}$ at a charge ratio of $20 \%$ for different rotational speeds.

When $N / N c$ is 0.5 or 0.6 , the centrifugal force is low due to the low rotational speed, so the pellets only slide in the disc rather than roll. Moreover, the location where the pellets are lifted is low, so the pelletizing process would not take place. When N/Nc is 0.8 or 0.9 , the pellets falls more far from the top of the disc to the bottom. The increase of height and the higher rotational speed give a high velocity to the pellets when the pellets move violently; furthermore, they are impacted from other pellets or disc wall, and they would be broken into pieces. Thus, the pelletizing effect is poor. When $N / N c$ is 0.7 , pellets can roll. Seed balls are rotating in fine iron ore powders; the fine powders should adhere to seed balls, and the seed balls then grow into pellets.

Figure 3 shows that the motion state of pellets simulated by DEM in the disco pelletizer. At $0.7 \mathrm{~N} / \mathrm{Nc}$, the motion state under different charging ratio is $1.2 \mathrm{~s}$. 


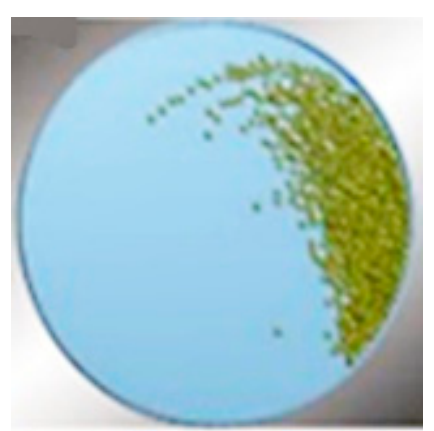

$10 \%$

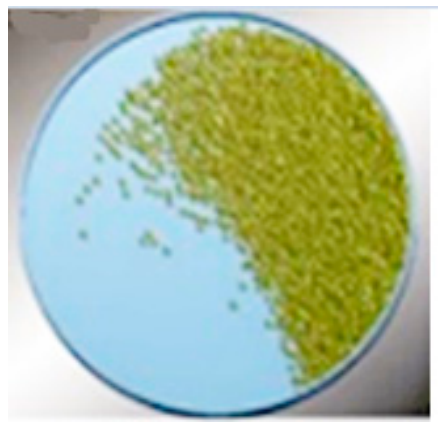

$20 \%$

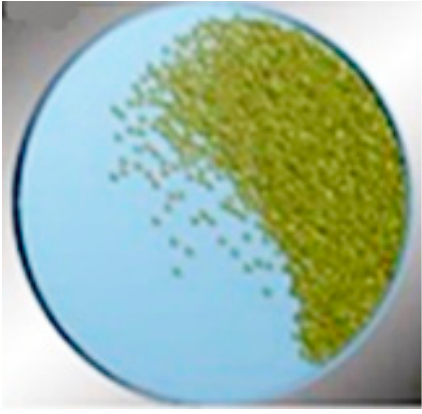

$15 \%$

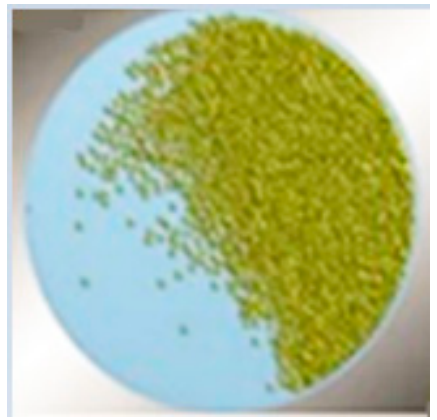

$25 \%$

Figure 3. Motion state of pellets is $1.6 \mathrm{~s}$ at $0.7 \mathrm{~N} / \mathrm{Nc}_{\mathrm{c}}$ for different charge ratios.

It can be clearly seen from Figure 3 that when the charge ratio is $10 \%$ or $15 \%$, due to the small number of pellets and a small area occupied by pellets in the disc, the utilization rate of the disc is not high, which reduces the efficiency of pelletizing. Moreover, due to the large space between the pellets, all the pellets are too loose, which increases the collision between the pellets, which in turn leads to the fragmentation of the pellets; this is not conducive to the pelletizing process. When the charge ratio is $25 \%$, the pellets near the disc wall move with the disc and do not fall when they reach the highest point. When the other pellets fall down, the phenomenon of multi-layer non-uniform rolling occurs, which is harmful to pelletization. Because the number of pellets is too high and the total kinetic energy is too large, the pellets falling later may crush the pellets falling earlier, which is not conducive to the pelletizing process. When the charge ratio is $20 \%$, the pellets have the best trajectory; that is to say, the seed balls can grow into pellets.

In order to investigate the behavior of pellets, the kinetic and rotational kinetic energies of pellets are calculated by using DEM, as shown in Figure 4 . The kinetic energy, $\mathrm{E}_{\mathrm{k}}$, and rotational kinetic energy, $\mathrm{E}_{\mathrm{r}}$, are given by the following equations, respectively:

$$
\begin{aligned}
\mathrm{E}_{\mathrm{k}} & =\frac{1}{2} \mathrm{mv}^{2} \\
\mathrm{E}_{\mathrm{r}} & =\frac{1}{2} \mathrm{I} \omega^{2}
\end{aligned}
$$

where $\mathrm{m}$ and $\mathrm{v}$ are mass and velocity of pellets, respectively, and I and $\omega$ are the moment of inertia and rotational velocity, respectively. 


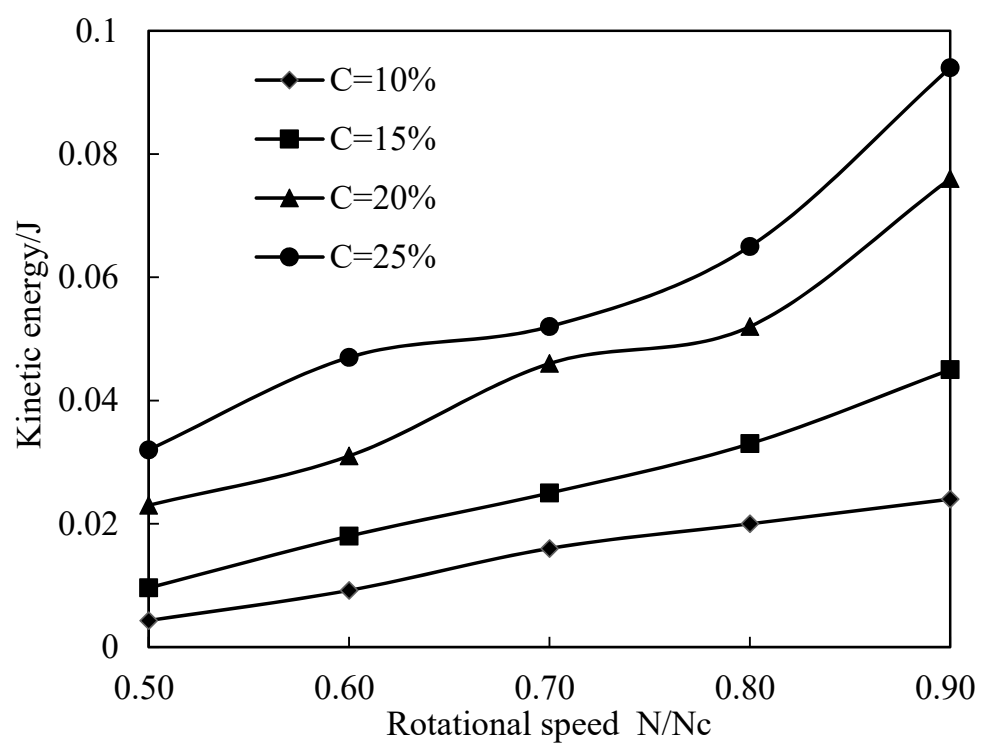

(a)

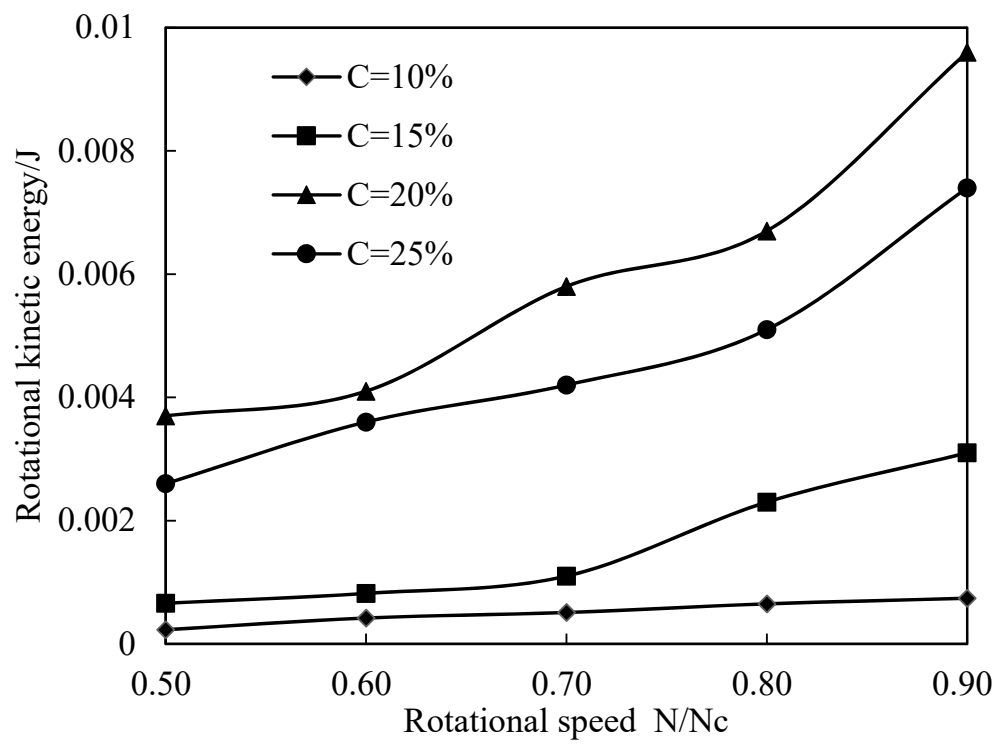

(b)

Figure 4. Effect of the rotational speed on (a) the kinetic energy and (b) rotational energy.

From Figure 4, it can be seen that the kinetic energy increases with the increase of the disc rotational speed and the charge ratio. Although the rotational kinetic energy increases with the increase of the disc rotational speed when the charge ratio is too high, such as up to $25 \%$, the rotational kinetic energy actually decreases with the increase of the charge ratio. As the charge ratio increases, it is difficult for each pellet to rotate itself due to being subjected to forces from all directions. This is the reason why the rotational kinetic energy decreases when the charge ratio is too high. Therefore, the proper charge ratio subjects the pellets to the best rotational kinetic energy, which is good for the growth of the pellets.

\section{Conclusions}

(1) The pelletizing process is not only related to the kinetic energy of the pellets, but also to the rotational kinetic energy. When the charge ratio is $20 \%$, the pellet has the best rotational kinetic energy, which is beneficial for pelletization. 
(2) When the disc tilt angle is $49^{\circ}, N / N c$ is 0.7 , and the charge ratio is less than $20 \%$, the pelletizing efficiency is low. When the charge ratio is $20 \%$, the best rotational kinetic energy can be obtained and the seed balls can grow into pellets. When the charge ratio is more than $20 \%$, the pellets will be broken.

Author Contributions: Conceptualization, F.L., F.S. and X.J.; Data curation, F.L., F.Y., Y.Z. and H.A.; Supervision, F.S.; Writing—original draft, F.L.; Writing—review \& editing, X.J. All authors have read and agreed to the published version of the manuscript.

Funding: This research was funded by the Scientific Research Plan of Education Department of Hubei Province (No. B2017002), National Natural Science Foundation of China (NSFC 52074074, NSFC 51874080, and NSFC 51974073) and the Fundamental Research Funds for the Central Universities (N2125036).

Institutional Review Board Statement: Not applicable.

Informed Consent Statement: Not applicable.

Data Availability Statement: Data sharing not applicable.

Acknowledgments: The financial support by the Scientific Research Plan of Education Department of Hubei Province (No. B2017002), National Natural Science Foundation of China (NSFC 52074074, NSFC 51874080, and NSFC 51974073) and the Fundamental Research Funds for the Central Universities (N2125036) are much appreciated.

Conflicts of Interest: The authors declare no conflict of interest.

\section{References}

1. Li, J.; Han, C.; Yang, A.; Liu, W.; Zhang, Y.; Liu, L.; Xiao, H. Effect of $\mathrm{MgO}$ on the performance of magnesian fluxed pellets. Sinter. Pelletizing 2017, 42, 31-37.

2. Lin, C.; Shen, H. The influence of burden structure on blast furnace smelting. In Proceedings of the 10th China Iron and Steel Annual Conference and the 6th Baosteel Academic Annual Conference, Shanghai, China, 21-23 October 2015; pp. 583-591.

3. Chen, Y.; Cheng, Z.; Zhen, P. Study on optimization of charge structure of large blast furnace. In Proceedings of the 15th National Big Bf Ironmaking Academic Annual Conference, Urumqi, China, 1-3 September 2014; pp. 48-150.

4. Shen, F.; Gao, Q.; Jiang, X.; Wei, G.; Zheng, H. Effect of magnesia on the compressive strength of pellets. Int. J. Miner. Metall. Mater. 2014, 2, 431-437. [CrossRef]

5. Gao, Q.; Shen, F.; Wei, G.; Jiang, X.; Zheng, H. Effects of MgO Containing Additive on Low-Temperature Metallurgical Properties of Oxidized Pellet. J. Iron Steel Res. Int. 2013, 20, 25-28. [CrossRef]

6. Zhu, D.; Chun, T.; Pan, J. Influence of Basicity and MgO Content on Metallurgical Performances of Brazilian Specularite Pellets. Int. J. Miner. Process. 2013, 125, 51-60. [CrossRef]

7. Zhu, D.; Gao, Z.; Pan, J.; Chun, T.; Yang, C. Influence of pellet basicity and $\mathrm{MgO}$ content on roasting and metallurgical properties of pellets. J. Cent. South Univ. Sci. Technol. 2013, 44, 3963-3970.

8. Xing, X.; Du, Y.; Zheng, J.; Wang, S.; Ren, S.; Ju, J. Isothermal Carbothermal Reduction of $\mathrm{FeTiO}_{3}$ Doped with MgO. JOM 2021, 73, 1328-1336. [CrossRef]

9. Dwarapudi, S.; Ghosh, T.; Shankar, A.; Tathavadkar, V.; Bhattacharjee, D.; Venugopal, R. Effect of pellet basicity and MgO content on the quality and microstructure of hematite pellets. Int. J. Miner. Process. 2011, 99, 43-53. [CrossRef]

10. Meraj, M.; Pramanik, S.; Pal, J. Role of $\mathrm{MgO}$ and its different minerals on properties of iron ore pellet. Trans. Indian Inst. Met. 2016, 69, 1141-1153. [CrossRef]

11. Silva, F.; Lemos, L.; Nogueira, P.; Bressan, M. Effect of ternary basicity of iron ore-fluxed pellets on melting and softening properties in a blast furnace. Metall. Mater. Trans. B 2021, 52, 69-76. [CrossRef]

12. Soda, R.; Sato, A.; Kano, J.; Kasai, E.; Saito, F.; Hara, M.; Kawaguchi, T. Analysis of Granules Behavior in Continuous Drum Mixer by DEM. ISIJ Int. 2009, 49, 645-649. [CrossRef]

13. Zhu, X.; Bai, C.; Han, J. Discussion on the Influence of the Parameters of Disc Pelletizer on the Qualified Rate of Green Pellet Size. In Proceedings of the 2012 Annual Meeting of National Sintering and Pelletizing Technology Exchange, Yinchuan, China, 24-26 May 2012; pp. 149-151. 